\title{
Development of a Coupled Ocean-Atmosphere-Wave-Sediment Transport (COAWST) Modeling System
}

\author{
John C. Warner ${ }^{\mathrm{a}, *}$, Brandy Armstrong ${ }^{\mathrm{a}}$, Ruoying He ${ }^{\mathrm{b}}$, Joseph B. Zambon ${ }^{\mathrm{b}}$ \\ ${ }^{a}$ US Geological Survey, Coastal and Marine Geology Program, Woods Hole Science Center, Woods Hole, MA 02543, United States \\ ${ }^{\mathrm{b}}$ Department of Marine, Earth and Atmospheric Sciences, North Carolina State University, Raleigh, NC 27695, United States
}

\section{A R T I C L E I N F O}

\section{Article history:}

Received 23 January 2010

Received in revised form 7 June 2010

Accepted 14 July 2010

Available online 29 July 2010

\section{Keywords:}

Coupled models

ROMS

SWAN

WRF

Sediment transport

\begin{abstract}
A B S T R A C T
Understanding the processes responsible for coastal change is important for managing our coastal resources, both natural and economic. The current scientific understanding of coastal sediment transport and geology suggests that examining coastal processes at regional scales can lead to significant insight into how the coastal zone evolves. To better identify the significant processes affecting our coastlines and how those processes create coastal change we developed a Coupled Ocean-Atmosphere-Wave-Sediment Transport (COAWST) Modeling System, which is comprised of the Model Coupling Toolkit to exchange data fields between the ocean model ROMS, the atmosphere model WRF, the wave model SWAN, and the sediment capabilities of the Community Sediment Transport Model. This formulation builds upon previous developments by coupling the atmospheric model to the ocean and wave models, providing one-way grid refinement in the ocean model, one-way grid refinement in the wave model, and coupling on refined levels. Herein we describe the modeling components and the data fields exchanged. The modeling system is used to identify model sensitivity by exchanging prognostic variable fields between different model components during an application to simulate Hurricane Isabel during September 2003. Results identify that hurricane intensity is extremely sensitive to sea surface temperature. Intensity is reduced when coupled to the ocean model although the coupling provides a more realistic simulation of the sea surface temperature. Coupling of the ocean to the atmosphere also results in decreased boundary layer stress and coupling of the waves to the atmosphere results in increased bottom stress. Wave results are sensitive to both ocean and atmospheric coupling due to wave-current interactions with the ocean and wave growth from the atmosphere wind stress. Sediment resuspension at regional scale during the hurricane is controlled by shelf width and wave propagation during hurricane approach.
\end{abstract}

Published by Elsevier Ltd.

\section{Introduction}

In the coastal zone, storms are one of the primary driving forces resulting in coastal change. These events create large waves, storm surges, flooding, coastal erosion, and strong currents that pose threats to life, property, and navigation. Utilizing our understanding of the processes that generate these effects and increasing our capability to predict these processes and their impacts will increase our ability to effectively manage and prepare for response to individual storm events, the cumulative effect of multiple storms, and long-term coastal change. This will allow planners and coastal managers to provide increased awareness and advanced preparation to minimize loss of life and property, and to provide capabilities for sustainable development to better manage coastal resources.

\footnotetext{
* Corresponding author. Tel.: +1 5084572237.

E-mail address: jcwarner@usgs.gov (J.C. Warner).
}

Due to the increased performance of computational resources, the use of numerical models to predict natural events is becoming more prevalent. To accomplish this, numerical models are not only being pushed to increase their spatial resolution but also to increase the complexity of the simulated physics. Coupling of models is one method to allow increase in model complexity. For example, advancements in the representation of nearshore dynamics have been achieved due to coupling of wave and ocean models (Lesser et al., 2004; Warner et al., 2008b). The coupling of models allows the effects of larger scale processes to directly influence the smaller scale response. Three-dimensional coupled atmosphere-ocean models have been developed and applied to idealized and realistic scenarios to predict the interactions between a tropical cyclone and the ocean (Bender and Ginis, 2000; Bender et al., 2007; Chen et al., 2007). Recently Fan et al. (2009a) investigated windwave-current dynamics and identified the significance of using an air-sea momentum exchange model to achieve dynamically consistent fluxes. 
To increase our capability to investigate impacts of storms on coastal systems, we have developed a coupled modeling system to investigate different physical process interactions. We began with a coupled modeling system as described in Warner et al. (2008b) and have further developed that system to include concurrent one-way grid refinement in the ocean model, concurrent oneway grid refinement in the wave model, coupling of an atmospheric model to include effects of sea surface temperature and waves, allow exchange of fields on refined grid levels, and provide interpolation mechanisms to allow the different models to compute on different grids. Because only prognostic variables are exchanged, the individual models can compute scalar and momentum fluxes that are not consistent between components. However, this allows sensitivity experiments to exchange prognostic variable fields between model components. A consistent flux coupler is being implemented for future release. The original components and the recent improvements are described in Section 2. In Section 3 we demonstrate the application of the modeling system and present results for an application to simulate Hurricane Isabel. We provide a summary and conclusions in Section 4.

\section{Methods}

The Coupled Ocean-Atmosphere-Wave-Sediment Transport (COAWST) Modeling System we developed is comprised of several components that include models for the ocean, atmosphere, surface waves, sediment transport, a coupler to exchange data fields, and a method for regridding (Fig. 1). We use all publicly available components. The Model Coupling Toolkit as the coupler to exchange data fields between the ocean model ROMS, the atmosphere model WRF, the wave model SWAN, and the sediment capabilities of the Community Sediment Transport Model. These components, improvements to individual components, and the coupling are described below.

\subsection{Ocean model}

The ocean model is the Regional Ocean Modeling System (ROMS), a general class of free surface, terrain-following numerical models that solve the three dimensional Reynolds-averaged $\mathrm{Na}$ vier-Stokes equations (RANS) using the hydrostatic and Boussinesq approximations (Shchepetkin and McWilliams, 2005, 2009; Haidvogel et al., 2008). ROMS uses finite-difference approx-

\section{COAWST Modeling System}

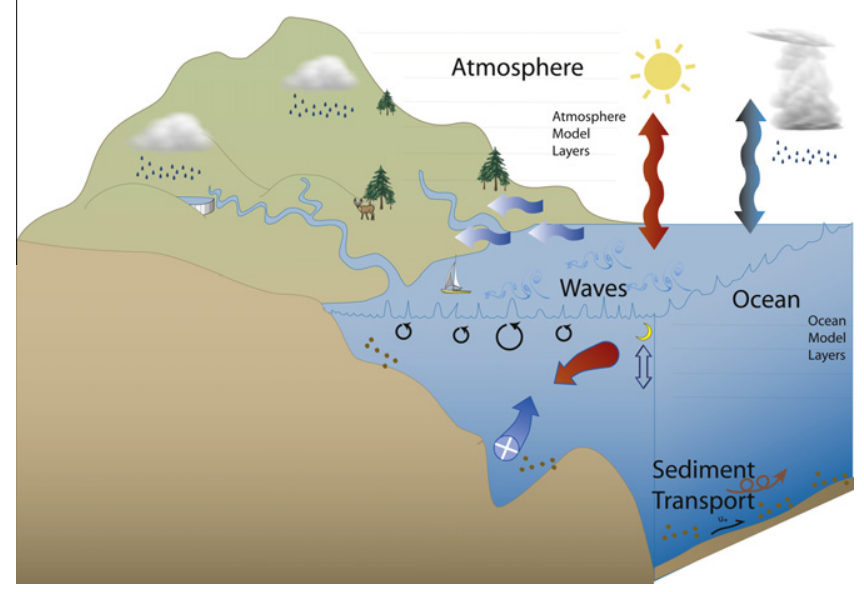

Fig. 1. The COAWST Modeling System comprising a coupler (MCT) that provides exchange between an ocean model, an atmosphere model, a waves model, and a sediment transport model. imations on a horizontal curvilinear Arakawa $\mathrm{C}$ grid and on a vertical stretched terrain-following coordinate. Momentum and scalar advection and diffusive processes are solved using transport equations and an equation of state computes the density field that accounts for temperature, salinity, and suspended-sediment contributions. ROMS provides a flexible structure that allows multiple choices for many of the model components such as several options for advection schemes (second order, third order, fourth order, and positive definite), turbulence models, lateral boundary conditions, bottom- and surface-boundary layer submodels, airsea fluxes, surface drifters, a nutrient-phytoplankton-zooplankton model, and an adjoint model for computing model inverses and data assimilation. The code is written in Fortran90 and runs in serial mode on a single processor, or uses either shared- or distributed-memory architectures (OpenMP or MPI) to run on multiple processors.

For this manuscript we have added a method for one-way grid refinement into the ROMS model. The method is based on an approach similar to a composed grid formulation by Warner et al. (in press). The terminology of grid refinement in this manuscript implies the methodology for structured grid models where there is a spatially large grid that encompasses the entire domain of interest. This large grid is called the master parent grid. Within the parent grid there are region(s) defined by the user that have increased grid resolution, typically by a factor of 3 or 5 . These are called child grids. There can be children within children, creating a hierarchy of grids that allow specific regions of variably increased resolution.

For our example application the parent grid is large enough to cover all of the domain of interest and has a set resolution to adequately resolve basin scale dynamics. We use a grid that covers the entire US East Coast and the Gulf of Mexico on a $\sim 5 \mathrm{~km}$ scale (Fig. 2, left panel). The spatial extent is large enough to allow dynamics of the Gulf Stream and the evolutions of tropical cyclones to be resolved within the domain. We developed a finer child grid for the Outer Banks and Cape Hatteras region in North Carolina with a scale factor of 5 , providing a refined grid on a $\sim 1 \mathrm{~km}$ resolution. The system is capable of handing multiple levels of grid refinement but only two (one parent and one child) are used for this application.

The one-way nesting is achieved as follows. The parent grid takes one complete baroclinic time step, which includes several barotropic steps. The prognostic variables of the coarse parent grid are then interpolated in space to fill boundary arrays for the next finer child grid. The boundary arrays include multiple alongboundary spatial cells to account for the fact that the different advection schemes require varying numbers of grid points to complete their stencil. The next level finer child grid can then take "Nrefined" (in our case 5) baroclinic time steps to advance the child grid in time to the same level as the parent. At that moment both parent and child grids are at the same time level and coupling to the other models (wave and atmosphere) would occur. For more than one child grid, the procedure is similar in that the parent and each child will take one step until the finest child grid is reached. Then the finest child grid must advance multiple times until it reaches a concurrent time as its parent. This approach continues with the children grids advancing until all the grids reach the master parent level.

An example of an application of the grid refinement is shown in Fig. 2, right panel. The colors display the sea surface temperature (SST) with arrows showing surface currents. The coarse parent grid is resolving the Gulf Stream and basin scale variability. The refined child grid (insert) allows increased resolution along the coastal region to resolve smaller scale dynamics and predicts a consistent SST and current pattern as the parent grid. This allows the region of interest to be resolved with an increased spatial resolution 


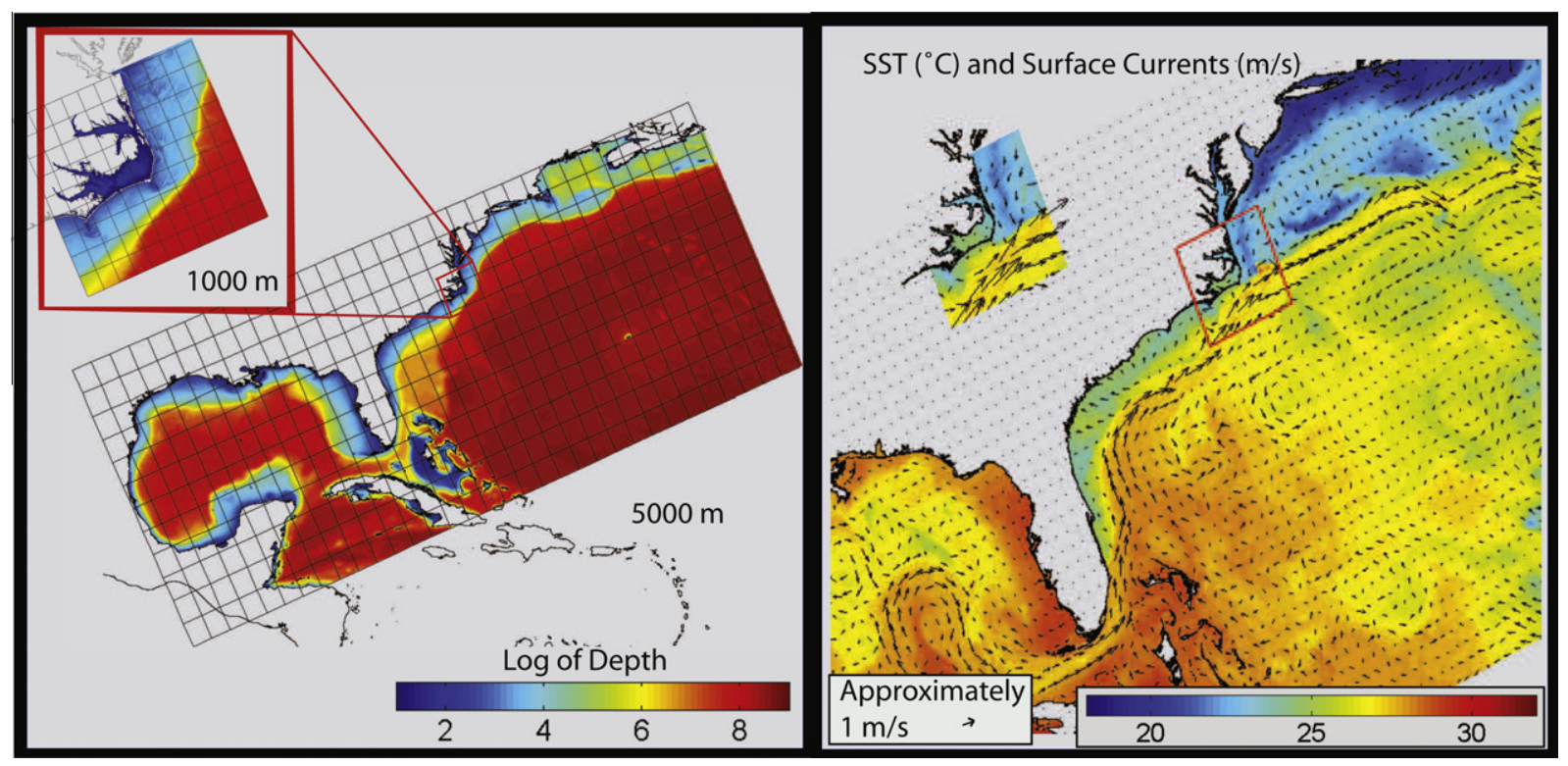

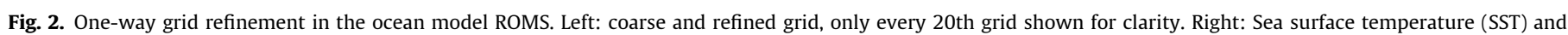
surface currents in the coarse and refined grids showing smooth transition of fields.

and be driven with forcings that are more dynamically consistent because the physics are being resolved on both grids with consistent formulations.

\subsection{Atmosphere model}

The atmospheric model component in the coupled system is the Advanced Research Weather Research and Forecasting (WRF) Model (ARW; Skamarock et al., 2005). It is a nonhydrostatic, quasi-compressible atmospheric model with boundary layer physics schemes and a variety of physical parameterizations of sub-grid scale processes for predicting meso- and microscales of motion. The model predicts three-dimensional wind momentum components, surface pressure, dew point, precipitation, surface sensible and latent heat fluxes, longwave and shortwave radiative fluxes, relative humidity, and air temperature on a sigma-pressure vertical coordinate grid. WRF has been used extensively for operational forecasts (http:// www.wrf-model.org/plots/wrfrealtime.php) as well as for realistic and idealized research experiments.

We have modified the WRF code to provide an enhanced bottom roughness when computing the bottom stress over the ocean. For the Mellor-Yamada Nakanishi Niino (MYNN) level 2.5 planetary boundary layer and associated surface layer scheme, the existing method in WRF uses a bottom roughness length scale computed based on the stress:

$z_{0}=c_{a} u_{*}^{2} / g+v / u_{*}$

where $z_{0}$ is the surface roughness, $c_{a}$ is the Charnok coefficient (0.016) that is typical for rapidly rising seas, $u^{*}$ is the surface stress, $g$ is gravity, and $v$ is the viscosity. We have modified the code to allow the MYNN option to include effects of waves based on the Taylor and Yelland (2000) formulation such that

$z_{0}=1200.0 H_{\text {wave }}\left(H_{\text {wave }} / L_{\text {wave }}\right)^{4.5}+0.11 v / u_{*}$

where $H_{\text {wave }}$ is the significant wave height and $L_{\text {wave }}$ is the mean wavelength. This option is activated when coupling to the wave model and was chosen as a representative method. Other methods can easily be implemented in future releases.

\subsection{Wave model}

The wave model is Simulating WAves Nearshore (SWAN). SWAN is a spectral wave model specifically designed for shallow water that solves the spectral density evolution equation (Booij et al., 1999). SWAN simulates wind wave generation and propagation in coastal waters and includes the processes of refraction, diffraction, shoaling, wave-wave interactions, and dissipation due to whitecapping, wave breaking, and bottom friction.

The wave model solves the action balance equation (Holthuijsen, 2008):

$\frac{\partial N}{\partial t}+\frac{\partial c_{x} N}{\partial x}+\frac{\partial c_{y} N}{\partial y}+\frac{\partial c_{\sigma} N}{\partial \sigma}+\frac{\partial c_{\theta} N}{\partial \theta}=\frac{S_{w}}{\sigma}$

where $N(\sigma, \theta, x, y, t)$ is the action density spectrum, $\sigma$ is the relative radian frequency (as observed in a frame moving with the ocean current), $\theta$ is direction normal to the wave crest, $x$ and $y$ are coordinate space (expressible in both spherical and Cartesian coordinates), and $t$ is time. The action density is defined as the wave energy density $(E)$ divided by the relative frequency $(N=E / \sigma)$ and is solved because action density is conserved in the presence of currents. The group velocities in $x$ - and $y$-directions $c_{x}$ and $c_{y}$ in the second and third terms represent propagation of action density in geographic space, the fourth term represents changes in relative frequency due to variations in depth and currents with a propagation speed $c_{\sigma}$ in frequency space, and the fifth term allows depthand current-induced refraction with a speed $c_{\theta}$ in directional space. The $S_{w}$ term represents source and sinks of wave energy density as described above.

SWAN allows input of time and spatial varying ocean currents and water level. In a previous effort (Warner et al., 2008b) the ocean model ROMS was coupled to SWAN. The coupling was developed for both models operating on the same grid. Prognostic fields that are exchanged between the models are described in Section 2.7. In the ocean model, the wave fields are utilized to compute forcings in the form of radiation stress gradients that allow wave-driven flows, to compute stokes velocities to provide correct mass flux transport, and to compute wave-enhanced bottom stresses. The wave model receives varying water levels, changes in bathymetry and bottom roughness (to simulate morphological 
variations due to sediment transport on the sea floor), and ocean currents. The ocean surface currents $\left(u_{s}, v_{s}\right)$ affect the wave action balance in two ways. One way is that the source term will use the $10 \mathrm{~m}$ wind speed $\left(U_{\text {wind }}, V_{\text {wind }}\right)$ from the atmosphere model modified by the local current (i.e. $U_{\text {wind }}-u_{s}, V_{\text {wind }}-v_{s}$ ) thereby modifying the wind stress (for example as in Kara et al. (2007)). A second way is to use the modified group velocities $\left(c_{x}+u_{s}, c_{y}+v_{s}\right)$ which in turn effects the wave number to allow current-induced refraction (see for example, Holthuijsen, 2008, Appendix D; Fan et al., 2009a).

The SWAN model does have an existing formulation for nesting, in which the user would run the parent grid and save data at locations inside the parent grid that define the perimeter of the first child grid. Once the parent simulation is completed, then the method would run the child grid with forcing obtained from the parent simulation, save data for the next grid down, and repeat. However, this method is cumbersome and because we use wave-current interactions, it would require the ocean model to be simulated in the same manner of saving boundary files to run finer child grids. We chose to develop a methodology that allows all the parent and child grids of both the ocean and wave models to operate concurrently so that wave-current interactions can occur at all spatial levels.

We have implemented a new method for grid refinement into the SWAN model to allow the parent and child grids to be simulated concurrently (at the same time). The methodology is similar to that described above for ROMS in that there is a master parent grid that covers the entire region of interest and child grids in regions of increased resolution. The user specifies the total number of grids (NGRIDS) that will be simulated concurrently. To accomplish this we modified the code to allow the use of pointers for the main variables. The pointers are categorized into Fortran groups called "TYPES". Each TYPE is then allocated with a dimension of NGRIDS. This allows each grid to be allocated with a different size.

To run the model the parent grid takes one time step. Then the wave action density is interpolated in space from the parent grid to locations that define the perimeter of the next finer child grid. The pointers are updated to point to the child grid level and then that next child grid can advance "Nrefined" time steps (5 for our example) until it reaches the same computational time as the parent. At this point there is no feedback to the parent (one-way grid refinement for now). The parent is then available to advance one step in time and the process continues. If there are multiple child grids, the procedure is the same except that each grid takes one step until the finest grid is reached. The parent grid can only advance when the finest grid has finished advancing to the same computational time. An example of the one-way concurrent grid refinement for SWAN is shown in Fig. 3. Here we see the significant wave height (colors) from Hurricane Isabel as it approaches landfall. The left panel shows the larger scale parent grid. The right panel is a combined view showing the parent and the child grid solutions, with the child grid outline with a dashed box. The child grid provides increased resolution of the wave heights and the wave fields are continuous from the parent through the child grid.

For the applications presented in this manuscript we chose to use the same grids at each level of refinement for the ocean model and the wave model. The modeling system we developed has the flexibility to allow the different models to operate on different grids. However this can complicate an application because it is not apparent how to handle non-overlapping parts of each domain.

\subsection{Sediment model}

The sediment modeling component is from the Community Sediment Transport Modeling System (CSTMS; Warner et al., 2008b). Currently these components are integrated into the ROMS model. However they are identified as a separate set of routines and can be extracted as a separate entity. The sediment routines consist of algorithms for suspended-sediment transport, bed load transport for current and wave-current forcing, enhanced bottom stress due to surface waves, a multiple bed model to track stratigraphy, morphology, and the ability to transport multiple sediment classes. These routines have been demonstrated to simulate a variety of inner shelf and estuarine sediment processes (Warner et al., 2008a; Harris et al., 2008; Ganju et al., 2009).

\subsection{Coupler}

The coupler is the Model Coupling Toolkit (MCT; Larson et al., 2004; Jacob et al., 2005) that allows the transmission and transformation of various distributed data between component models using a parallel coupled approach. MCT is a program written in Fortran90 and works with the MPI communication protocol. It is compiled as a set of libraries, which are linked during the compilation. During model initialization each model decomposes its own domain into sections (or segments) that are distributed to processors assigned for that component. Each grid section on each processor initializes into MCT, and the coupler compiles a global map to determine the distribution of model segments. Each segment also initializes an attribute vector that contains the fields to be exchanged and establishes a router to provide an exchange pathway between model components. During the run phase of the simulation the models will reach a predetermined synchronization point, fill the attribute vectors with data, and use MCT_send and _receive commands to exchange fields. Further details are described in Warner et al. (2008c).

\subsection{Regridding}

For the application presented below the wave and ocean models operate on the same grids and the atmosphere model runs on a grid with a larger spatial extent. To allow the models to exchange data fields on different grids we use the Spherical Coordinate Remapping Interpolation Package (SCRIP; Jones, 1998) to compute interpolation weights. The weights are computed as a pre-processing step. They are read in during initialization, and used in the sparse matrix interpolation as described in Warner et al. (2008b). Currently we use the nearest neighbor method to compute the weights. Fig. 4 shows an example of regridding. In the left panel the atmosphere model has a spatial extent that covers most of the continental United States, Mexico, and Caribbean Islands. The atmosphere grid is large enough to provide surface forcing for the ocean and wave models, but the ocean and wave model grids are rotated and with different cell sizes. The interpolation is required to transfer data between these grids. Also, as shown in the right panel (Fig. 4), the ocean model cannot provide a full spatial field of SST to the atmosphere model. Therefore the atmosphere model must also acquire data from other sources. For this application we used data from the Global Forecasting System (GFS: http://dss.ucar.edu/datasets/ds083.2/) to provide complete surface fields for the atmosphere model. Then, the GFS data is replaced by any fields that came from the ocean or wave model. This allows data from different sources to be combined to allow a full coverage of fields. The combined data may need to be blended along the boundaries to provide a seamless coverage. For the applications presented here no blending was performed.

\subsection{Modeling system operation}

The build scripts for the individual systems were modified such that the coupled system is compiled to produce one single executable. The modeling system runs in MPI and before execution the 

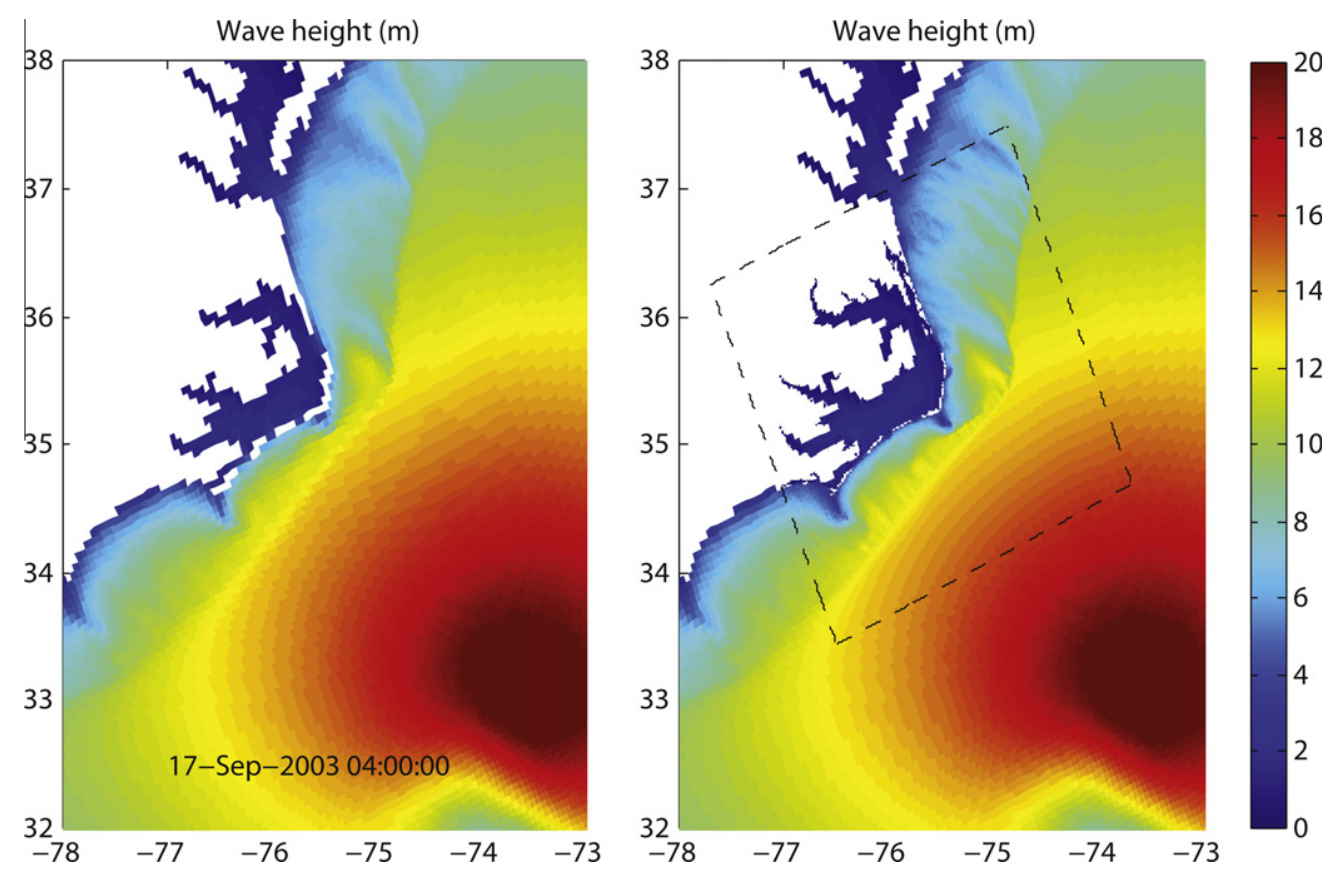

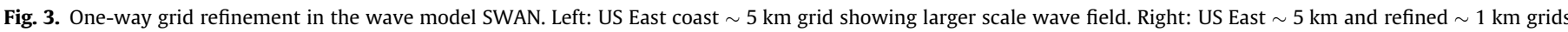
(dashed box shows outline). Colors are wave heights.
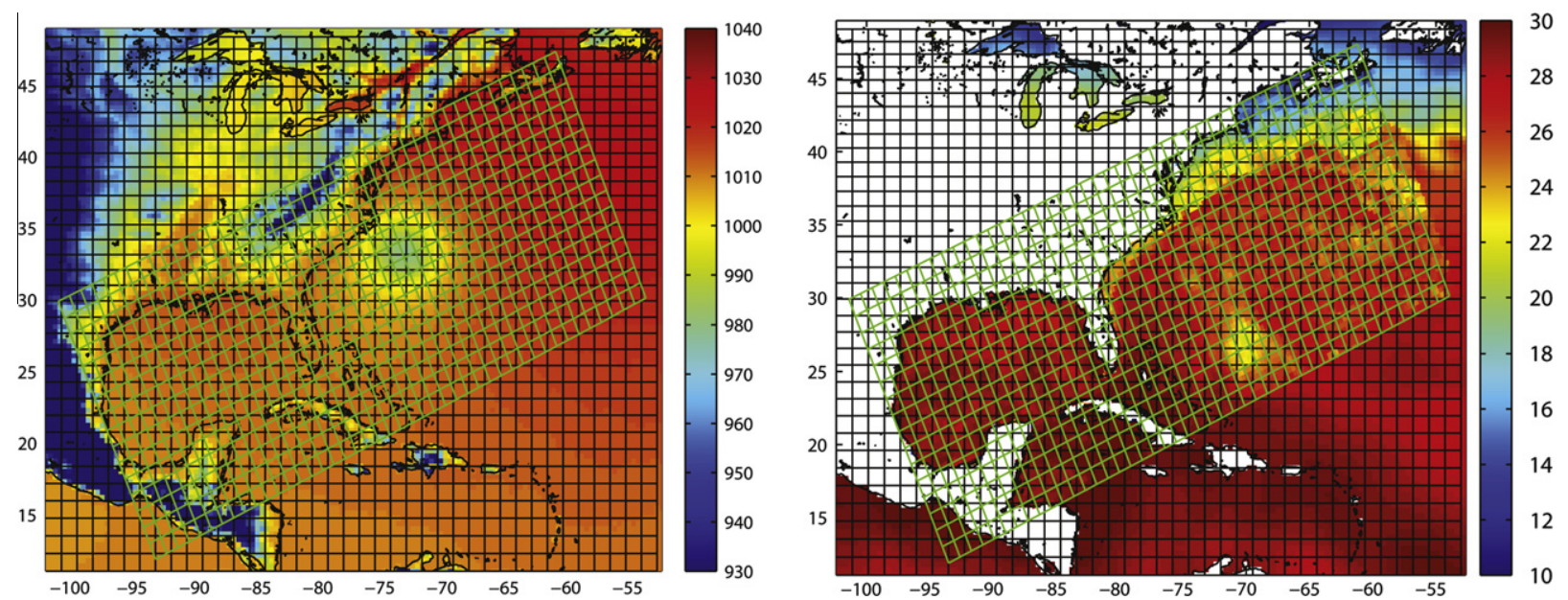

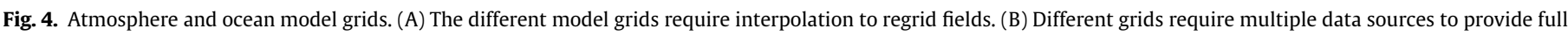
spatial coverage of data for the larger domain.

user sets the number of processors that will be allocated for each model (ocean, atmosphere, and wave). During initialization each processor from each model initializes with MCT (as described previously) and MCT identifies the distribution of model components on all the processors. MCT can then determine the grid distributions. During execution the models will advance in time until they reach a user defined synchronization point. At that time each model fills its attribute vector to exchange prognostic variables through MCT to other models.

The variables that are exchanged are shown in Fig. 5. Panel 5D shows the data fields exchanged for the fully coupled system. The atmosphere model provides $10-\mathrm{m}$ surface winds ( $\left.U_{\text {wind }}, V_{\text {wind }}\right)$ to the wave and ocean models. The atmosphere also provides to the ocean model the atmospheric pressure $\left(P_{\text {atm }}\right)$, relative humidity $(\mathrm{RH})$, atmospheric surface temperature $\left(T_{\text {air }}\right)$, cloud fraction (cloud), precipitation (rain), shortwave $\left(\mathrm{SW}_{\mathrm{rad}}\right)$ and longwave $\left(\mathrm{LW}_{\mathrm{rad}}\right)$ net heat fluxes. The ocean model uses these parameters in the COARE algorithm (Fairall et al., 1996) to compute ocean surface stresses and ocean surface net heat fluxes. The ocean model provides SST to the atmosphere model. The ocean provides surface currents $\left(u_{\mathrm{s}}, v_{\mathrm{s}}\right)$, free surface elevation $(\eta)$, and bathymetry (bath) to the wave model. The surface currents are averaged using a formulation of Kirby and Chen (1989) that integrates the near-surface velocity over a depth controlled by the wave number. The wave model provides significant wave height $\left(H_{\text {wave }}\right)$ and wave length ( $\left.L_{\text {wave }}\right)$ to the atmosphere and the ocean models. The atmosphere model uses these wave values to compute an enhanced sea surface roughness as described in Eq. (2). The wave model also provides to the ocean model wave direction $\left(D_{\text {wave }}\right)$, surface and bottom periods $\left(T_{\text {surf }}, T_{\text {bott }}\right)$, percent wave breaking $\left(Q_{b}\right)$, wave energy dissipation $\left(W_{\text {dissip }}\right)$, and bottom orbital velocity $\left(U_{\mathrm{b}}\right)$. These parameters are used by the ocean model in the COARE algorithm to provide an increased surface roughness and in the sediment transport algorithms for bed load transport and bottom stress mobilization. The 


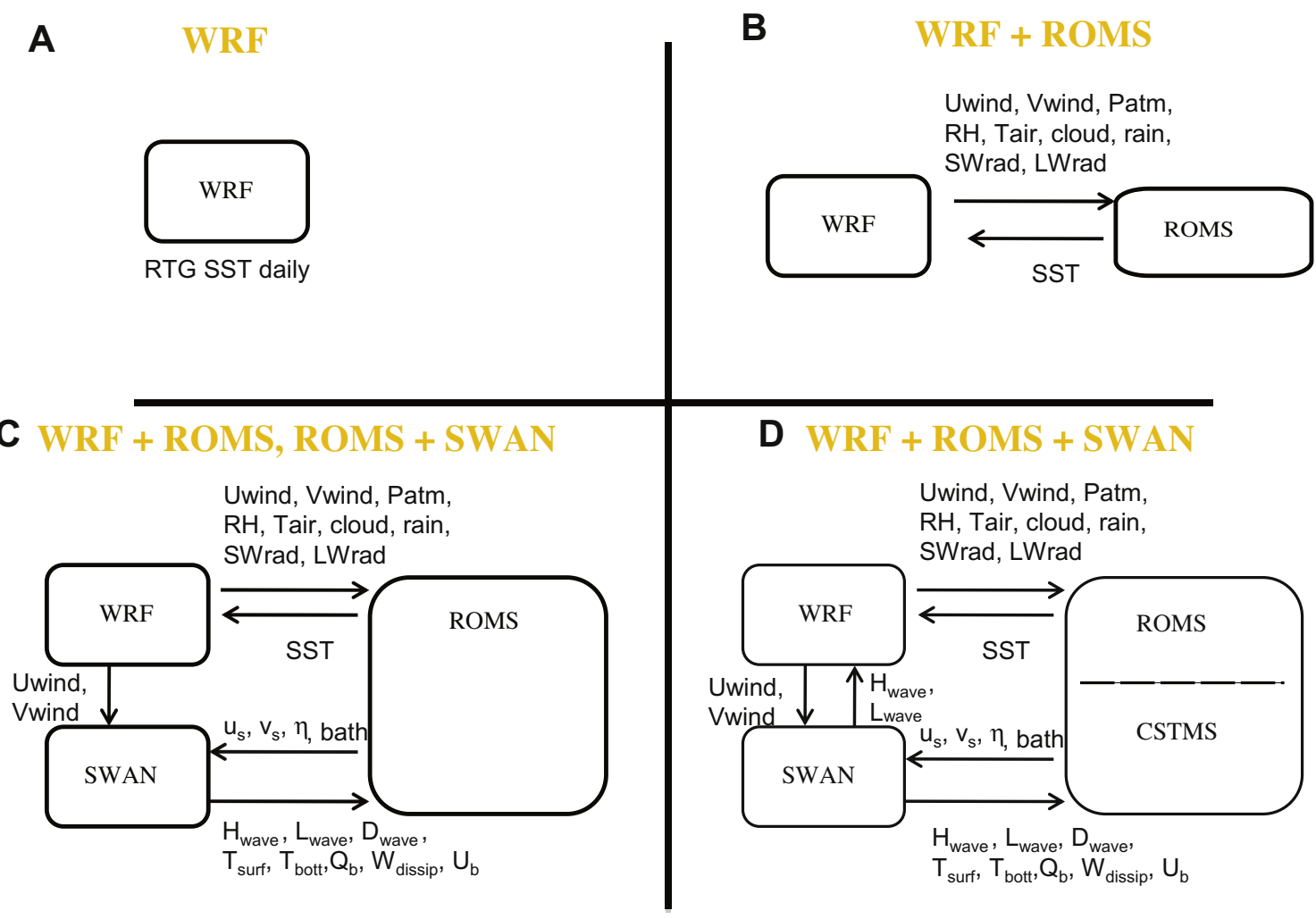

Fig. 5. Definition of four test applications showing configurations of data fields exchanged. Lower right panel (case D) shows all the fields that can be distributed.

wave parameters are also available to compute wave-driven flows, however, these processes are not activated in this application. The sediment model can provide spatially-varying bottom roughness as different grain sizes are mobilized and transported. The varying roughness is fed back to the ocean and wave models.

The current configuration of the coupled system provides exchanges of data fields between the different models. This will allow the system to test model sensitivity by varying the exchange of prognostic variable fields between different components. However the exchange of data fields does not necessarily provide a consistent set of fluxes exchanged between each model. Below we investigate the effect of exchanging different prognostic variables. Future release of the modeling system will have a consistent flux coupler capability.

\section{Application}

The system is applied to investigate dynamics during Hurricane Isabel. The hurricane reached Category 5 status on the Saffir-Simpson Scale and made landfall as a Category 2 slightly north of Cape Lookout on the US East Coast on September 18, 2003 at approx $1700 \mathrm{~h}$. Results for the hurricane best track were obtained from the National Weather Service Tropical Cyclone Report on Hurricane Isabel (http://www.nhc.noaa.gov/2003isabel.shtml).

\subsection{Model setups}

All the simulations were initialized to start with a model time of September 15, 2003. Initial conditions for the ocean model fields of currents, depth-averaged currents, water level, salinity, and temperature as well as lateral boundary conditions for currents, salinity, and temperature are obtained from the global HYCOM simulation (http://hycom.coaps.fsu.edu/thredds/catalog.html). During the simulation, the interior temperature and salinity were nudged to the tracer fields from HYCOM with a time scale of 20 days. Simulations without nudging revealed that nudging did not greatly affect the ocean model response for this experiment, an expected result since this was only a several day simulation. Five tidal constituents of the M2, N2, S2, O1, and K1 were imposed on the lateral open boundaries with constituents obtained from the ADCIRC tidal data base (Mukai et al., 2001).

Initial conditions for the wave model are obtained by running the model for a steady state simulation using North America Regional Reanalysis (NARR) winds. The boundary conditions for this initial stationary steady state simulation and the non-stationary simulation were obtained from the NOAA NCEP Wave Watch 3 model output archive (ftp://www.polar.ncep.noaa.gov/pub/history/waves/). Fields of wave height, period, and direction were interpolated to points along the open boundary of the wave model to create parametric 'TPAR' files. These files were used by SWAN to compute Jonswap spectra during the simulation.

Initial and boundary conditions for the atmosphere model were obtained from global forecasting system (GFS) 1 degree data NCEP Final Analysis (http://dss.ucar.edu/datasets/ds083.2/). Simulations (not shown) using only this coarse grid data for initial conditions yielded hurricanes that were too low in intensity. Attempts to use a simple vortex formulation for an initial condition provided hurricanes with appropriate intensity but resulted in trajectories that were severely diverted. The best alternative for our experiment was to provide the simulation with an initial condition based on realistic conditions from the GFS data but modified to account for the lack of intensity due to the coarse grid data. We chose to modify the initial conditions to provide a more realistic condition by adjusting the wind and pressure fields ( $U_{\text {wind }}, V_{\text {wind }}$, and PMSL) to be scaled to have maximum values consistent with observations from the National Hurricane Center (http://www.nhc.noaa.gov/ 2003isabel.shtml). The scaling occurs over a radius of $600 \mathrm{~km}$ starting from the center of the hurricane and extending radially outward. This adjustment maintained the original location as 
provided by GFS but scaled to allow increased initial intensity. Additional boundary conditions for sea surface temperature were obtained from NCEP Real-time Global (RTG) SST analysis (Gemmill et al., 2007; ftp://polar.ncep.noaa.gov/pub/history/sst) and were updated hourly. The WRF model was simulated using two grids. The parent grid was $790 \times 720$ cells in the east-west and northsouth direction, respectively, with a cell size of $6 \mathrm{~km}$. The model was simulated using a dynamic vortex following inner refined grid that was $300 \times 300$ cells at a $2 \mathrm{~km}$ resolution. The inner grid moved after each model time step based on the location of the hurricane.

The sediment model was initialized with zero sediment concentrations in the water column. The sea floor was initialized with a uniform distribution of 1 grain size of $0.17 \mathrm{~mm}$ ( 2 phi) fine sand with a settling velocity of $18 \mathrm{~mm} / \mathrm{s}$, density of $2650 \mathrm{~kg} \mathrm{~m}^{-3}$, and a critical stress for erosion of $0.17 \mathrm{~N} \mathrm{~m}^{-2}$. This sediment class is representative of sea-floor material on the inner shelf in this region.

All models were simulated from September 15 to 21, 2003. The ocean model was time stepped with a $30 \mathrm{~s}$ increment and used 16 vertical levels. The wave model used a time step of $10 \mathrm{~min}$ with 60 directional and 24 frequency bins. The atmosphere model used 27 vertical levels and was time stepped with a $30 \mathrm{~s}$ increment. All models were synchronized hourly to exchange data fields through the MCT coupler during the simulation.

\subsection{Results and analysis}

The coupled system was run in several configurations, with increasing degree of complexity. Many scenarios were simulated but only four cases are described here (Fig. 5). (1) WRF: Just the WRF model with a dynamic (i.e. time varying) SST consisting of a daily update from the NCEP RTG SST analysis (http://www.polar.ncep.noaa.gov/sst/). (2) WRF-ROMS: The system with WRF and ROMS coupled. (3) WRF-ROMS, SWAN-ROMS: WRF, ROMS, and SWAN but no wave fields from SWAN to WRF. (4) Fully Coupled: the fully coupled system with fields exchanged between all models and running the sediment model. It should be noted that none of these simulations include any type of strong data assimilation techniques. These methods are available in several of the components of the modeling system to provide steering during the simulations. Our goal was to investigate the variation in response of the modeling system as different physical interactions were activated. The differences in model results would be more difficult to ascertain if strong nudging and assimilation methods had been introduced.

\subsection{Atmosphere results}

\subsubsection{Hurricane tracks}

Results comparing the hurricane paths are shown in Fig. 6 for the observations and model cases. In the observed (verification) trajectory, on September 15 at 0000 the hurricane is located near longitude -67.9 and latitude 24.3 and is heading in a W-NW direction. Shortly thereafter the hurricane track turns NW and heads directly towards the Outer Banks, making land fall slightly north of Cape Lookout. All of the model cases begin at the same location on September 15 and they all tend to follow the turn to the NW. After the turn, in general, all cases follow the NW trajectory and head towards the Outer Banks. The WRF only case (blue line ${ }^{1}$ ) makes the furthest north landfall, approximately $150 \mathrm{~km}$ north of the actual landfall. As stated earlier, there was not a strong attempt to correct these paths with strong data nudging, rather a commit-

\footnotetext{
${ }^{1}$ Please note that Figs. 6-8, 12 will appear in $\mathrm{B} / \mathrm{W}$ in print and color in the web version.
}

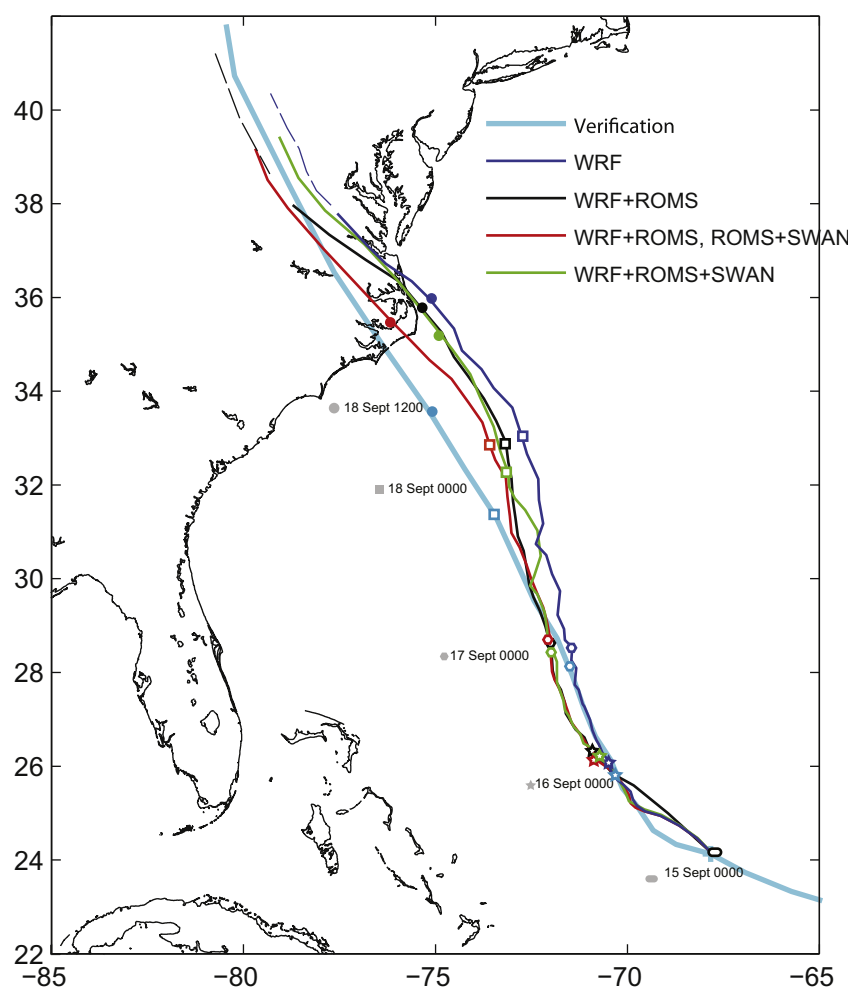

Fig. 6. Hurricane tracks and timings for the observed and four model scenarios.

ment to investigate the variability that develops as additional physics are activated. The coupled WRF-ROMS case (black line) allowed SST from ROMS to affect the atmosphere and created a slight adjustment of the path to the south. Increasing the model interactions by adding waves from the SWAN model to ROMS (red line) further adjusts the path to the south. The final case with full 3-way coupling allows waves to affect WRF (green line) and the path deviates back to the north. The cause of this will be discussed more below.

The timing of the storms is shown with symbols along the path lines. The cyan markers on the cyan lines identify the observed locations of the hurricane at $0000 \mathrm{~h}$ on each day from 15 to $18 \mathrm{Sep}-$ tember. Also shown is the location at hour 1200 on 18 September. The other colored symbols on their respective lines identify the location of the hurricane for that simulation. In general all of the modeled storms translate faster than observed. All of the different coupling cases generate storms that travel at approximately the same rate, except for the Fully Coupled case which travels slower (green marker on the green line lags the other numerical simulation markers). The modeled hurricanes make landfall about $6 \mathrm{~h}$ early, except for the Fully Coupled case which makes landfall about $4 \mathrm{~h}$ earlier than observed. All of the hurricanes increased in speed as they approached landfall.

\subsubsection{Hurricane intensity}

Results comparing the hurricane intensities are shown in Fig. 7. The intensity along the observed path (cyan line) starts at approximately $938 \mathrm{mb}$ pressure on 15 September and decreases to nearly $960 \mathrm{mb}$ on 16 September 1200. The hurricane demonstrates a slight increase in intensity to $953 \mathrm{mb}$ on 18 September and then quickly diminishes as it makes landfall. The numerical simulations all start with intensities near the best track on 15 September. All the model intensities decrease to nearly $955 \mathrm{mb}$ showing an adjustment from the initial conditions. The WRF only case (blue line) decreases to approximately $952 \mathrm{mb}$ and then shows a slight intensification to $945 \mathrm{mb}$ until 18 September and then decreases 


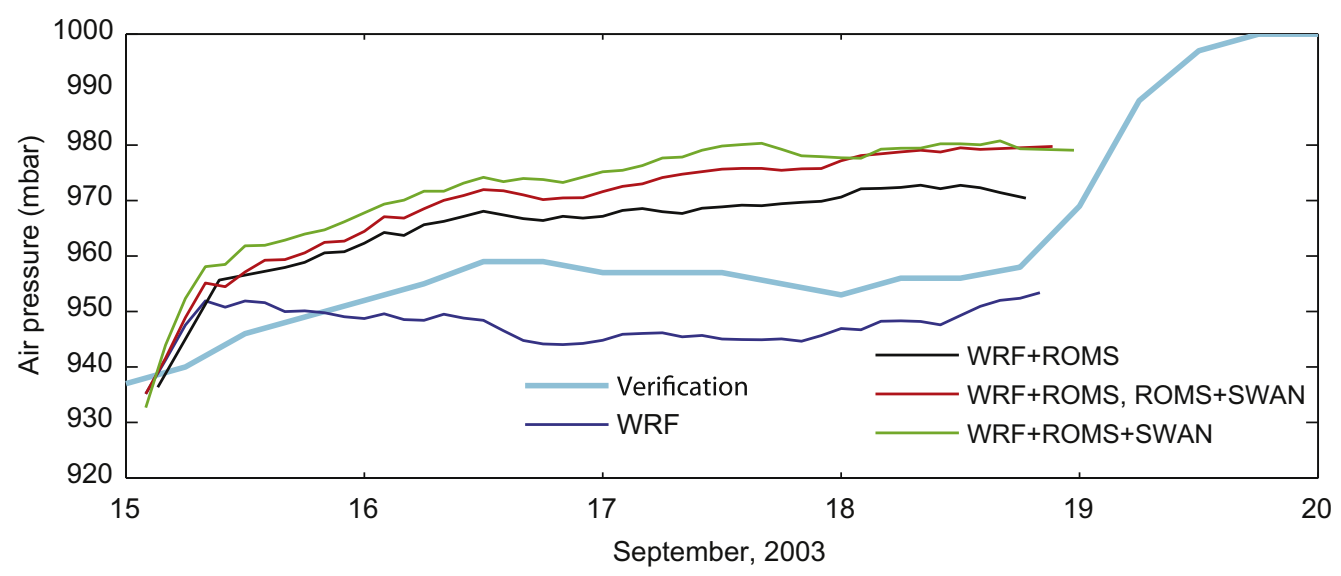

Fig. 7. Hurricane intensity time series for the observed and four model scenarios.

approaching landfall. This case was actually more intense than observed. For the other cases, in general, increasing the model interactions reduces the intensity. For the WRF-ROMS case (black line) the intensity is approximately $10-15 \mathrm{mb}$ too weak. As the waves from SWAN are introduced to ROMS (red line), the intensity is again reduced and for the Fully Coupled case (green line) the intensity is reduced even further. The trend of the track lines (moving south) and the intensities (decreasing) were consistent as more physical processes interacted except for the Fully Coupled case. For this last case the track moved back to the north but the intensity continued to decrease.

\subsubsection{Hurricane strength}

As with the intensity relations, the hurricane strengths (based on maximum wind speeds) follow similar trends (Fig. 8). The observed best track (cyan line) demonstrates sustained winds of $70 \mathrm{~ms}^{-1}$ until 15 September, and then shows approximately a linear decrease until 17 September. The winds then level off at
$45 \mathrm{~ms}^{-1}$ until landfall on 18 September when they begin to decrease dramatically. The WRF only simulation (blue line) shows an approximately constant wind speed near $60 \mathrm{~ms}^{-1}$ until landfall, greater than the best track. This increased strength is consistent with the slightly greater intensity (lower pressure). As other components of the system are included, the strength decreases initially and then maintains a nearly constant value from 16 to 18 September. The WRF-ROMS simulation (black line) demonstrates a decrease in wind speed to approximately $50 \mathrm{~ms}^{-1}$. With adding waves to ROMS (red line) the wind speed continues to decrease, and finally the Fully Coupled case (green line) has a decrease in wind speed to $35 \mathrm{~ms}^{-1}$. All of the simulations show increasing strength between September 17 and 18 as the hurricane is still in deep water before it reaches the continental shelf edge. Also shown are the Hurricane Research Division (HRD; http:// www.aoml.noaa.gov/hrd/index.html; Powell et al., 1998) winds (magenta line). These winds are derived from multiple sources of data including aircraft, ships, buoys, etc. For this time series the

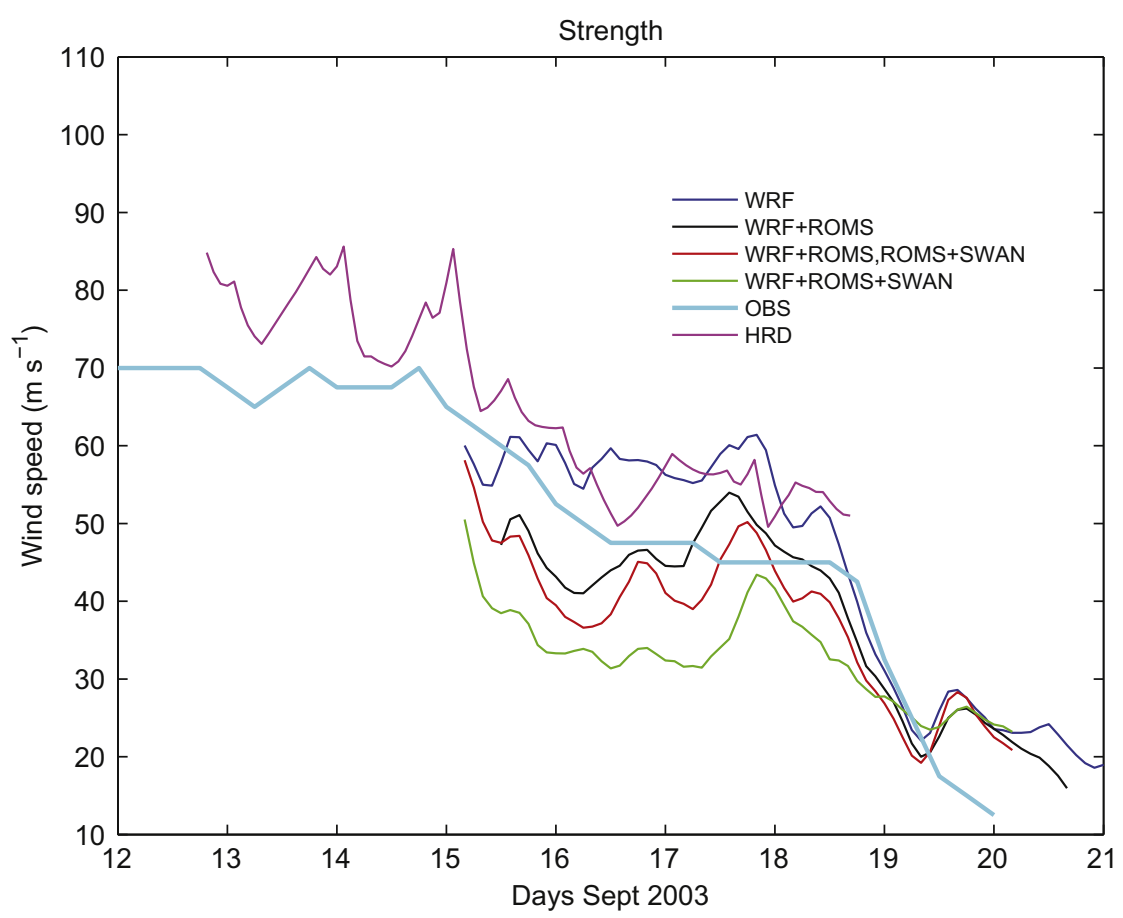

Fig. 8. Maximum wind speeds for the observed and four model scenarios, also including the HRD winds. 
peak winds shown are stronger than the observed best track time series. The HRD winds will be used to drive the wave model in a section to follow.

\subsubsection{Bottom stress}

The atmospheric bottom stress is computed in the MYNN surface layer scheme. The stresses for the different configurations on day 18 September hour 0000 are shown in Fig. 9. For the WRF only simulation (upper left) the bottom stress reaches over $2 \mathrm{~N} \mathrm{~m}^{-2}$ and the eye is well defined. Coupling WRF-ROMS (upper right) allows feedback of SST to the atmosphere model. This feedback provides a reduced SST (as a result of the hurricane-forced ocean upwelling) for the atmosphere as compared to the WRF only simulation and reduces the intensity and strength, hence the surface stress. Adding the coupling of waves to the ocean model (lower left) further reduces the stress. This is caused by waves increasing ocean mixing, and therefore further reducing the ocean SST. The reduced SST causes a reduced intensity and strength which create a lower surface stress. The Fully Coupled model (lower right) allows the waves to feed back into WRF. This fully coupled simulation demonstrates a slight increase in atmospheric surface roughness over the previous simulation. The waves feeding to the atmosphere model create an increased roughness length $\left(z_{0}\right)$. Even though the wind speed is lower, the total stress is slightly increased.

\subsection{Ocean results}

\subsubsection{Surface stress}

For the coupling method currently implemented the prognostic variables are exchanged between the different models. This can al- low the different models to compute different derived quantities such as stress or fluxes. For example the atmosphere model and the ocean model will compute different stresses at the air-sea interface. The surface stress for the ocean model (Fig. 10) demonstrates strong variability depending on the level of coupling. For the WRF-ROMS case (upper right), on September 18 the stress reaches nearly $3 \mathrm{~N} \mathrm{~m}^{-2}$ with increased stresses located in regions of increased strength. Increasing the level of coupling to allow the waves from SWAN into the ocean model (lower left) creates a greatly increased surface stress. For this case the wind strength was slightly reduced (as shown previously) but the increase in surface stress is due primarily to the increased surface roughness from the waves. This is consistent with the WRF simulation of adding waves to WRF in that it had the same effect of increasing the stress. Adding waves to WRF for the fully coupled system (lower right) decreases the surface stress in the ocean model because the wind strength from WRF is weaker and also the waves are weaker (because they are driven by the winds).

\subsubsection{Sea surface temperature}

The sea surface temperature (SST) also varies significantly between the different coupling cases (Fig. 11). For the WRF only case (upper left) the SST is updated every $12 \mathrm{~h}$ from a global RTS data set of $1^{\circ}$ resolution. On 18 September there is a slight evidence of the hurricane track near $28^{\circ}$ lat $-72^{\circ}$ lon with a temperature of about $25.5^{\circ} \mathrm{C}$. For the WRF-ROMS coupled case (upper right) the hurricane track is now completely visible in the form of a cool wake, with a decrease in SST to nearly $24^{\circ} \mathrm{C}$. By increasing the complexity of the coupling, adding waves from SWAN to ROMS (lower left) shows a greater decrease in SST to almost $21^{\circ} \mathrm{C}$. This
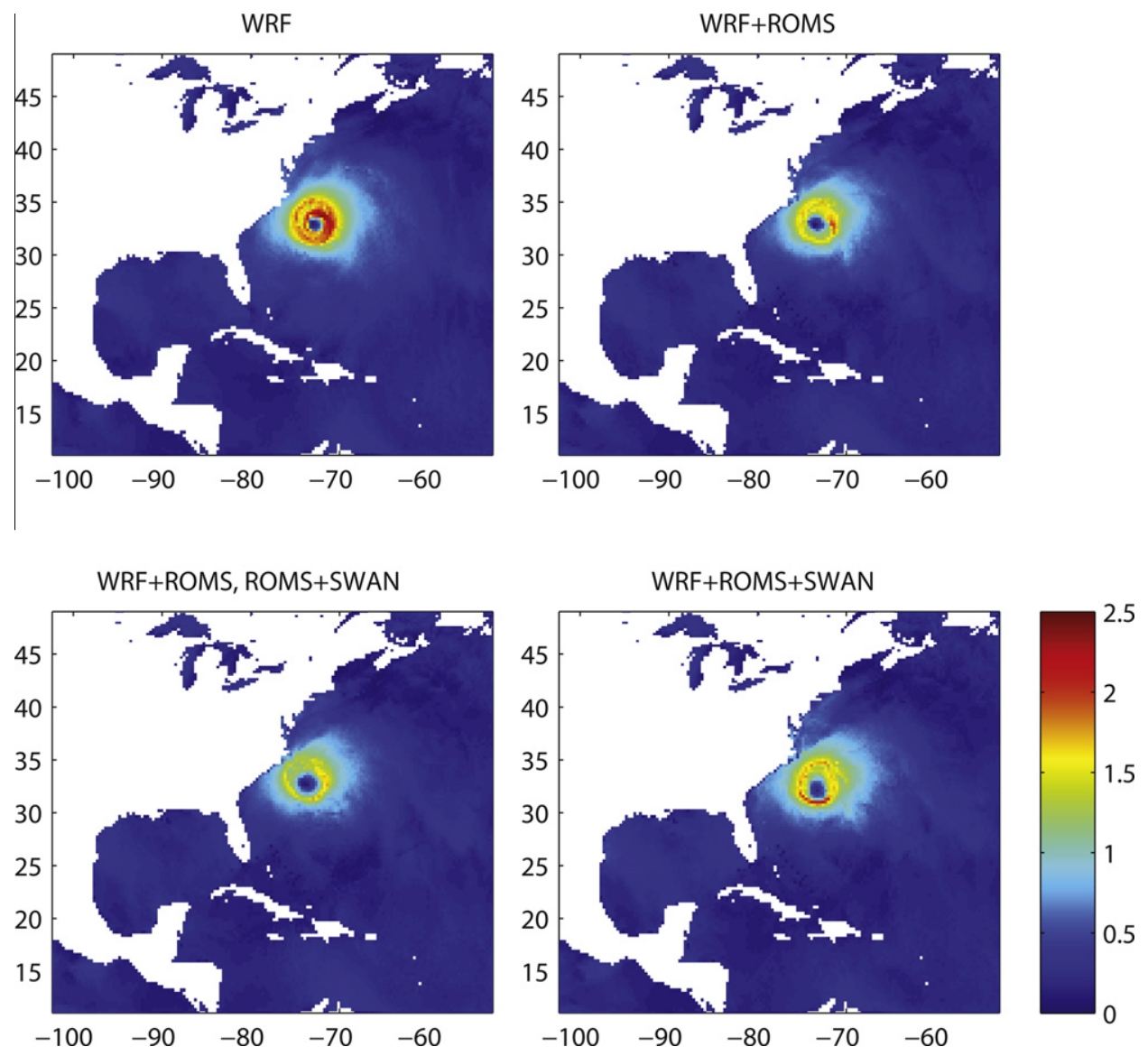

Fig. 9. Bottom stress $\left(\mathrm{N} \mathrm{m}^{-2}\right)$ of the atmosphere model for the four model scenarios at 18 September $0000 \mathrm{~h}$. 


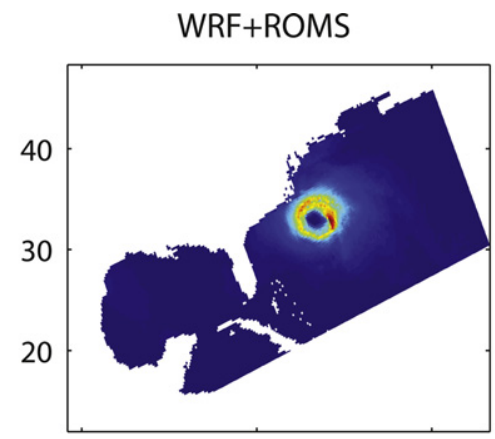

WRF+ROMS, ROMS+SWAN

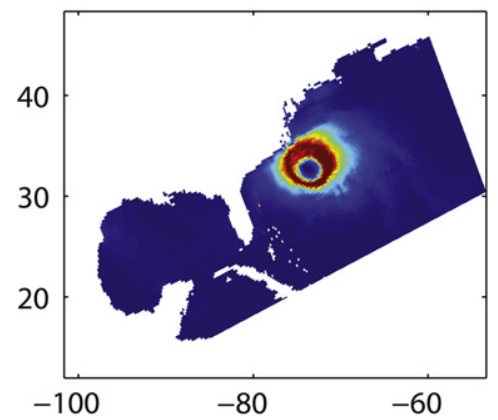

WRF+ROMS+SWAN

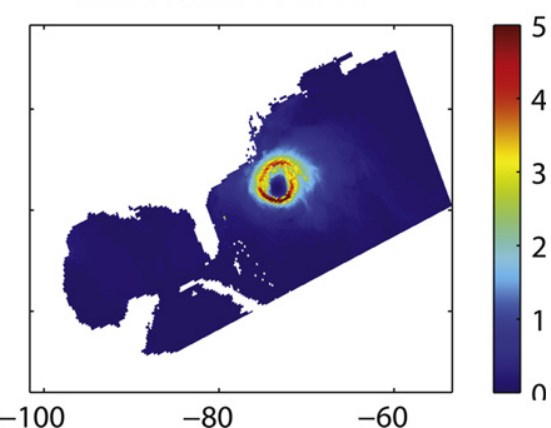

Fig. 10. Ocean surface stress $\left(\mathrm{N} \mathrm{m}^{-2}\right)$ for the four model scenarios at 18 September $0000 \mathrm{~h}$. (upper left was WRF only and did not have an ocean component).

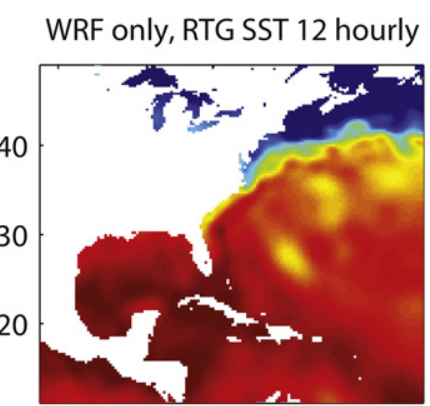

WRF+ROMS, ROMS+SWAN

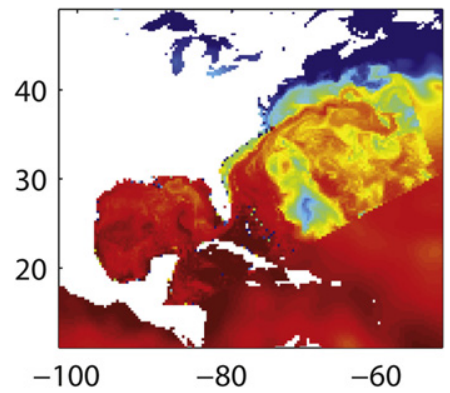

WRF+ROMS

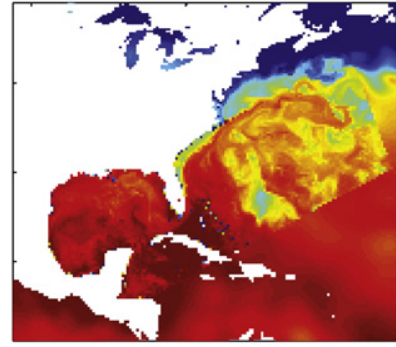

WRF+ROMS+SWAN

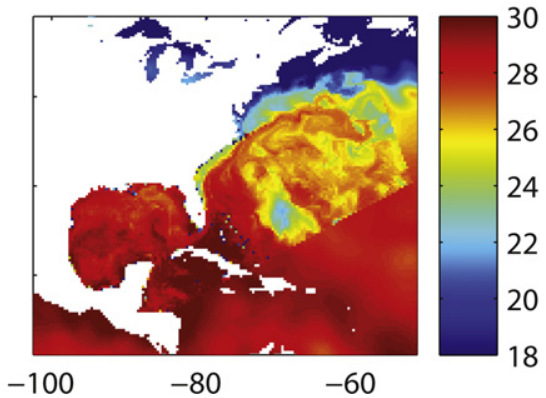

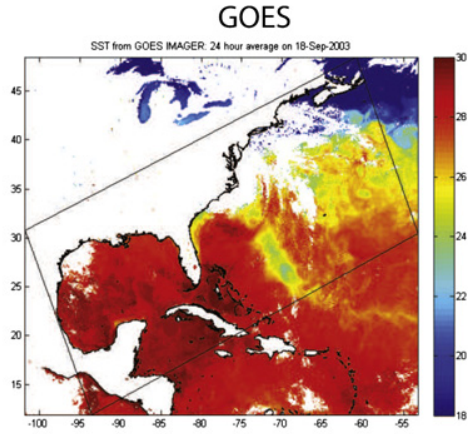
3 .

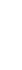
.

. 
locations and 1 buoy near the coast. The offshore buoys begin to show impact of propagating swell near September 16. The 41001 buoy observation has a peak near the middle of the 18th because it is farthest from the track. The buoy 41002 is close to the track and peaks just before the hurricane passes. The 41025 buoy was also close to the track and stopped recording data after September 18. The FRF buoy recorded the entire event and measured peak wave heights just slightly after landfall. Comparing the model results to the simulations shows strong differences amongst the simulations. For the simulations that have been discussed so far, only the cases that used SWAN can be shown. This includes the WRFROMS, ROMS-SWAN case (red line). For this case the magnitudes of wave heights are in general agreement with the observations; however the timing of the peak is too early because the hurricane was propagating too fast (as demonstrated previously). For the Fully Coupled case (green line) the wave heights are reduced because the hurricane intensity and wind speeds were less than the previous simulation due to enhanced surface roughness. As an additional simulation, a SWAN only simulation was forced with a blended NARR + HRD wind field (blue line). This simulation produces wave heights that are too large at all the offshore buoys. The combined wind field was shown to have wind speeds that were greater than the best track winds and this may be the cause of the larger wave heights. The coupled simulations produce waves that are closest to the observed. However, the wind fields for those simulations were weaker than observed.

Wave heights are also affected by the currents (Fig. 13). Typically tidal inlets and narrow passageways with strong currents identify locations of significant wave-current interaction. However, the Gulf Stream also contains strong currents parallel to the coast with speeds over $1 \mathrm{~ms}^{-1}$. As such they can also be affected by waves. As waves encounter a current, the current will create refraction of the wave field. The refraction will change the direction of the wave propagation and cause non-linear interactions. As the hurricane approaches landfall, the wave heights increase to over $20 \mathrm{~m}$ (Fig. 13, left side). The waves that propagate in a direction opposing the currents will be the strongest effected by the currents. The currents will reduce the wave propagation speed creating a decrease in the wave length. Fig. 13 right side shows the difference in wave heights between a simulation where the wave model was provided with the currents minus a simulation where the currents were not provided to the wave model. The waves increased by as much as $20 \%$ when the currents are allowed to interact with the wave model. Similar results were obtained by Fan et al. (2009b) for simulations of Hurricane Ivan. However Fan et al. identified a reduction in the wave heights when including
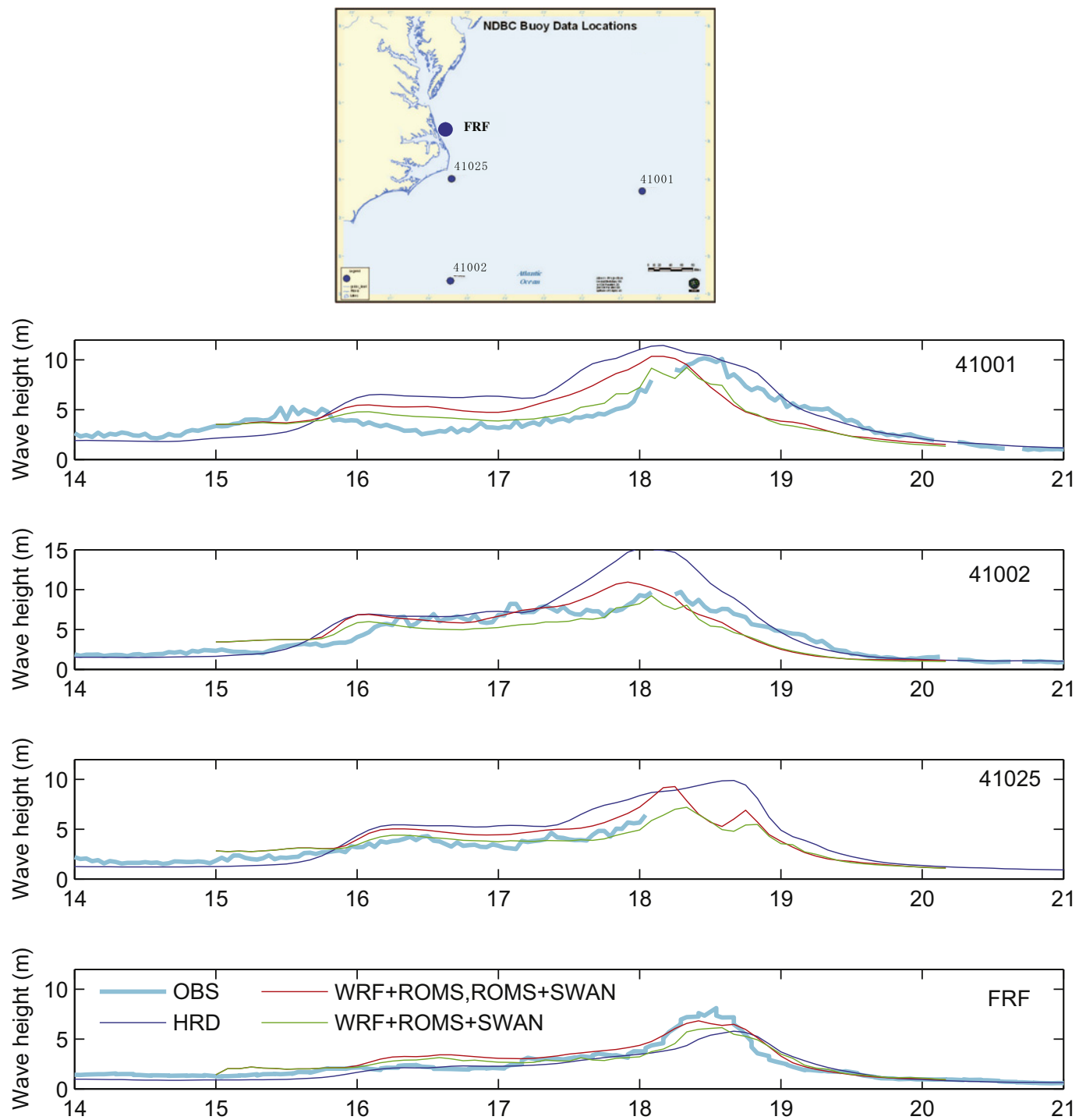

Fig. 12. Comparison of wave height time series for the 4 model scenarios. 

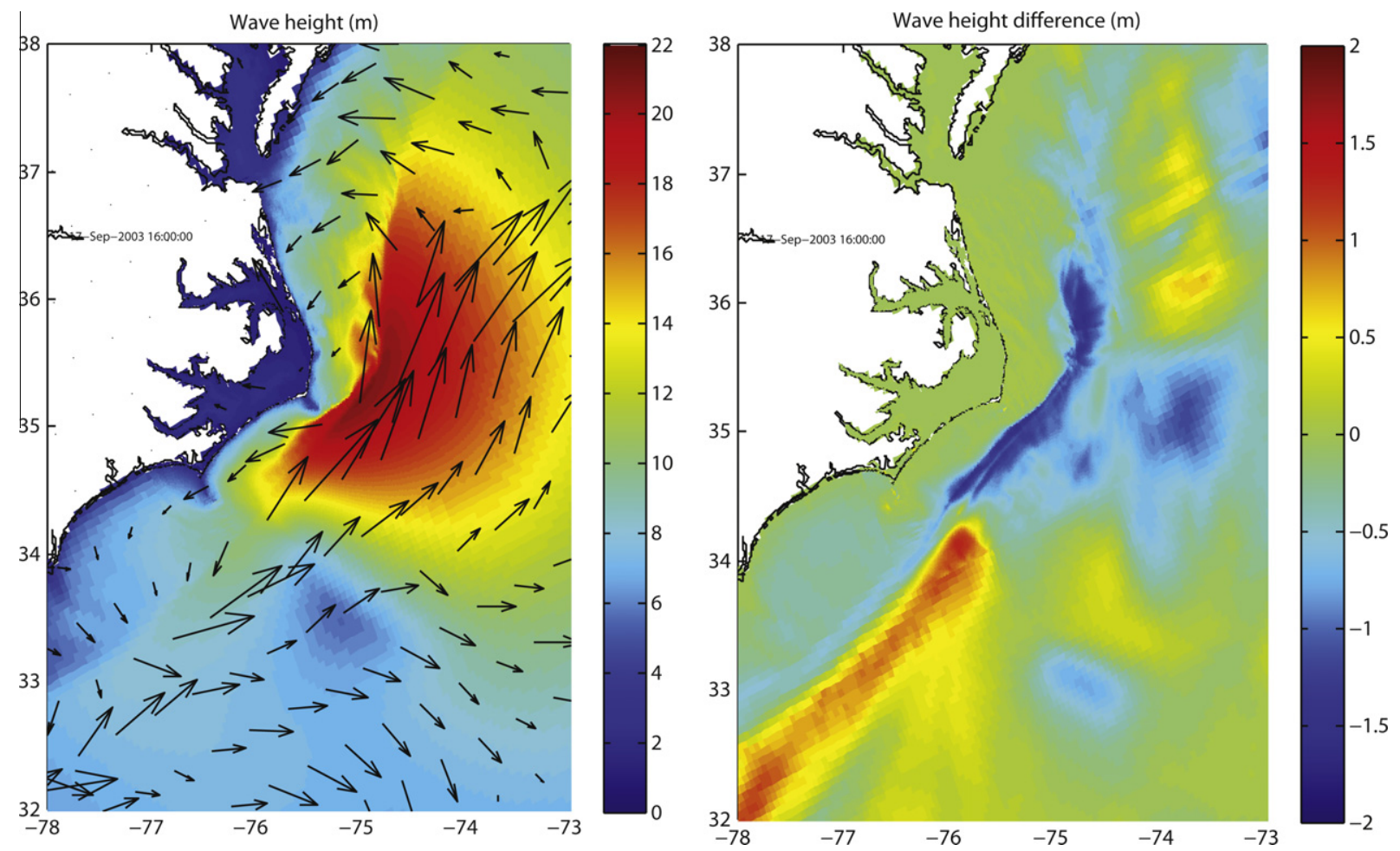

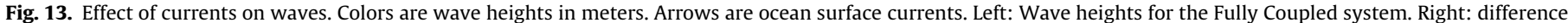
in wave heights if the currents are not allowed to affect the wave model (note difference color scale).
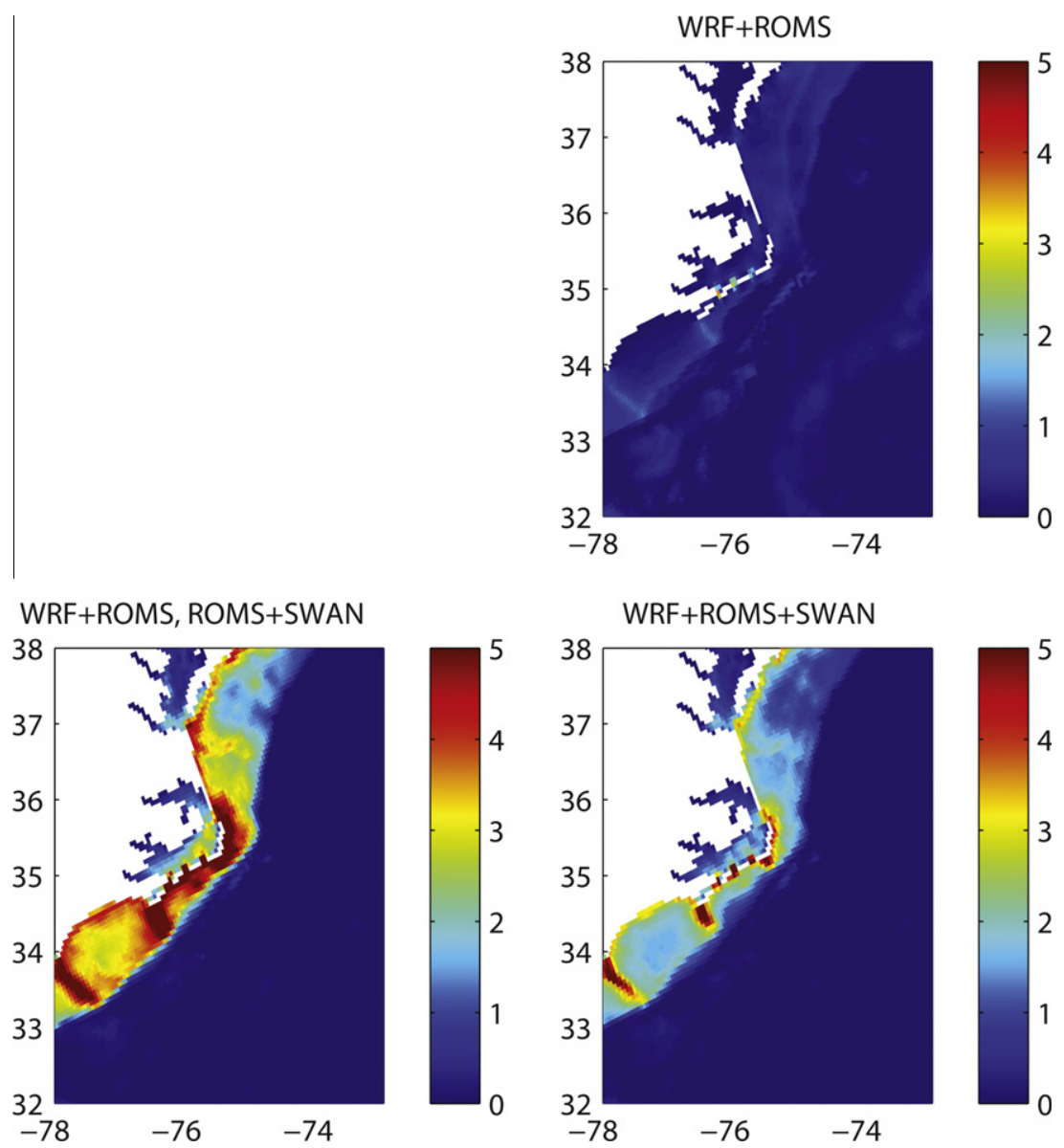

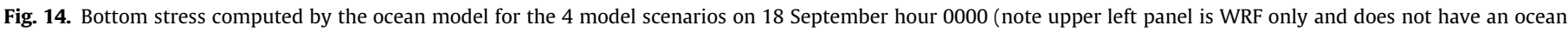
component). 
the effects of currents because the waves and currents were in the same direction. For our scenario, the waves and currents were predominately in the opposite direction (waves to the southwest opposing a northeastward Gulf Stream) and led to an increase in these wave heights.

\subsection{Sediment results}

\subsubsection{Ocean bottom stress}

The sediment transport is controlled largely by the bottom stress computed in the ocean model. The various cases allow a comparison of the impact on bottom stress (Fig. 14 for day 18 September). For the WRF-ROMS case there was no wave model, so the bottom stress is due only to the ocean currents and is greatly reduced, showing a maximum peak value over the inner shelf of approximately $2 \mathrm{~N} \mathrm{~m}^{-2}$. With the inclusion of waves to the ocean model, the WRF-ROMS ROMS-SWAN simulation shows a greatly increased bottom stress with maximum values on the Cape shoals and on the inner shelf adjacent to the landfall region. The maximum combined wave-current stress is over $5 \mathrm{~N} \mathrm{~m}^{-2}$. For the Fully Coupled case the bottom stress is slightly reduced because the wind strength is slightly diminished resulting in reduced waves and this relates to reduced orbital velocities on the sea floor, reducing the bottom stress. The maximum stress is slightly less than $5 \mathrm{~N} \mathrm{~m}^{-2}$ with the greatest values on the Cape associated shoal features and in the tidal inlets.

\subsubsection{Sediment response}

The sediment response is described only for the Fully Coupled case. Results for the other simulations are similar in their response but different in magnitude. This is mainly due to the variability of the bottom stress as described above. As the hurricane approached landfall, the wave heights are over $10 \mathrm{~m}$ on September 18 (Fig. 15, upper left). The waves are stronger in the right front quadrant of the hurricane, but the waves affect the entire US East coast. The waves create an enhanced bottom stress along the entire coast (Fig. 15, upper right). The maximum bottom stress is not necessarily correlated with the location of maximum wave heights because of differences in water depth. The maximum waves are offshore of Cape Hatteras in deeper water. As the waves propagate, the oscillatory motion is distributed down through the water column. In deeper water the waves do not feel or affect the sea floor. As the waves propagate landward, however, they impinge on the ocean bottom and lose energy through dissipation due to bottom friction. This energy loss is converted to mechanical energy for sediment transport. The stress is strong on the shallower regions at the shoals off the Carolina Capes. Large stresses are also seen at the Nantucket Shoals and Georges Bank off Cape Cod. These features persist year-round and are largely associated with strong tidal currents (e.g. Loder, 1980; Loder and Greenberg, 1986; He and Wilkin, 2006). The inner shelf sediment is responding to the increased bottom stress due to waves (Fig. 15, lower left). The suspended sediment shows large concentrations across the entire inner shelf with greatest values near the location of landfall. Increased resuspension is also visible off Cape Cod where the stresses were high. The model can track the change in bed elevation due to the sediment mobilization, transport, and deposition. After landfall the bed thickness (Fig. 15, lower right) shows predominant erosional patterns along the inner shelf north of Cape Hatteras all along the eastern seaboard. Strong erosion also occurred off Cape Cod on Georges Bank. South of Cape
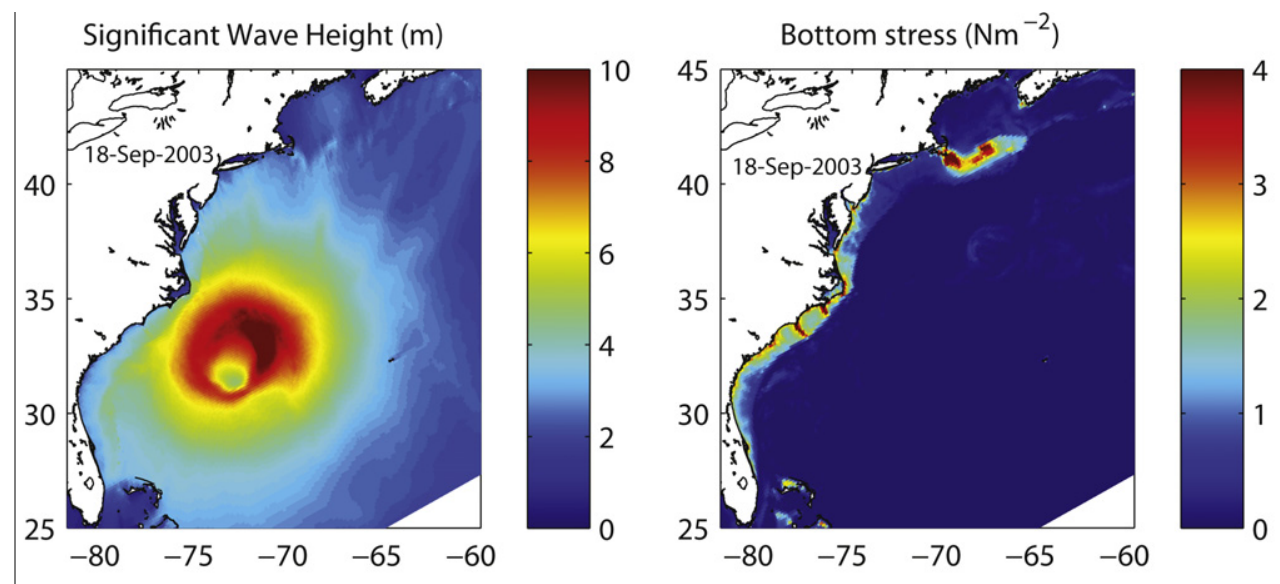

log Susp.-sediment conc. $\left(\mathrm{kg} \mathrm{m}^{-3}\right)$
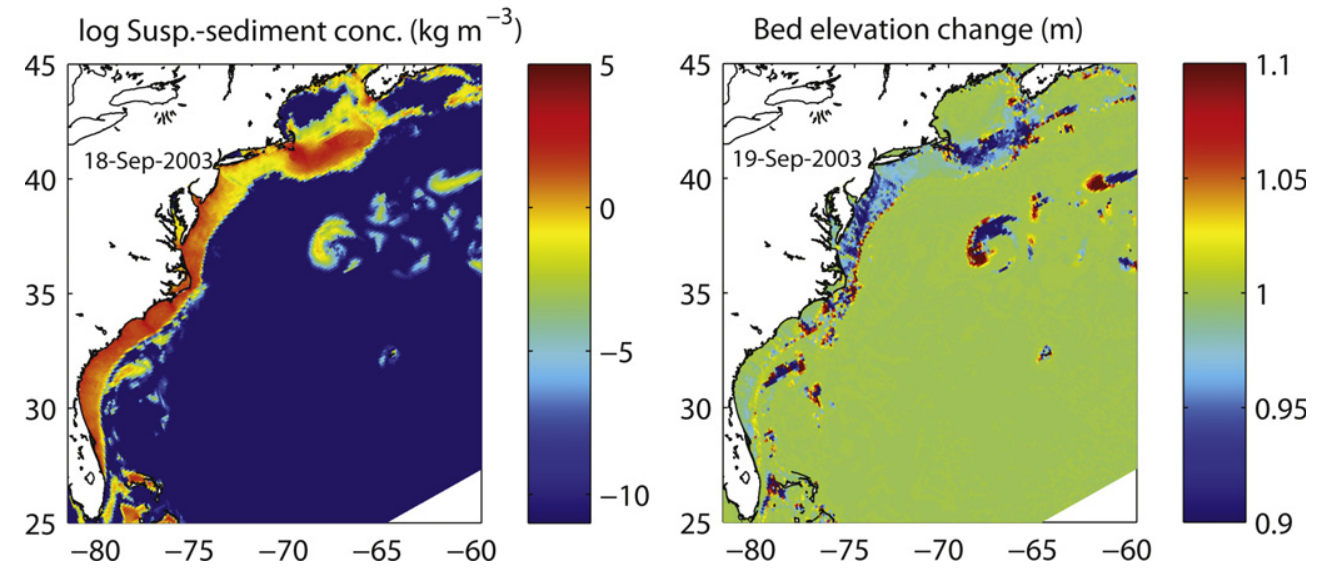

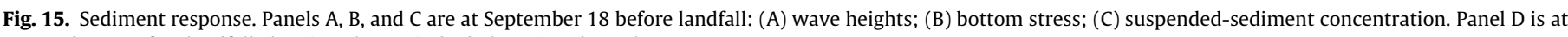
September 19 after landfall showing change in bed elevation along the US East coast. 
Hatteras there is erosion on the north face of the Cape associated shoals and deposition on the southern face of the shoals. The location of maximum erosion is consistent with the location of maximum stress. Bed elevations closer to the hurricane path in Onslow Bay show changes on the order of 5-10 cm, consistent with observations (Wren and Leonard, 2005).

\section{Summary and conclusions}

A newly Coupled Ocean-Atmosphere-Wave-Sediment Transport Modeling System has been developed that allows exchange of prognostic variables between the atmosphere model WRF, the ocean model ROMS, the wave model SWAN, and a sediment transport modeling routines CSTMS. Methodologies of grid refinement allow increased grid resolution at user defined locations. The SCRIP package provides interpolation weights to allow the different models to run on independent grids.

The system was applied to simulate Hurricane Isabel to explore insight into the effects of activating different processes on the individual components. The feedbacks ultimately create non-linear interactions between different components and can make it difficult to assess the full impact on each specific model. However there are certain characteristics that can be identified.

The hurricane simulation of just WRF alone provided an intensity that was too strong and was driven by a SST that was too warm, and the track was the furthest to the north. By increasing the model interactions and allowing coupling to the ocean model, the SST became more realistic and the track moved closer to the correct path, but the cooler water reduced the hurricane intensity. SST was best simulated by the coupled system, but this tended to produce intensities and wind speeds that were too low. Adding waves to the ocean model increased the surface roughness, increased surface mixing of the ocean, and increased bottom stress on the sea floor. Adding the waves to the ocean model also reduced the bottom stress of the atmosphere model. This is because the waves increased the $z_{0}$ value for the ocean surface, which increased the surface mixing and provided a cooler SST to the atmosphere. The increased mixing may be attributed to the lack of upper limit on the roughness computation. Consequently, the hurricane intensity and strength are reduced, resulting in reduced bottom stress from the atmosphere. Adding waves to the atmosphere model increased the bottom roughness for the atmosphere. However, this further reduced the strength.

Waves were best simulated with the coupled system, but these simulations included winds that were reduced from those observed, thus identifying that the wind-wave growth formulations may overestimate wave growth in strong wind applications. Sediment is most correctly simulated using the coupled system because the waves are necessary to compute enhanced bottom stress. The sediment response to the hurricane extended along the entire US East Coast and across the inner shelf.

The individual modeling systems were developed independent of these coupling efforts. While this study represents an important and promising step to couple three different state-of-the-art community models (WRF, ROMS, SWAN), the inclusion of the dynamical feedback has identified weaknesses in the models for coupling applications. By only exchanging prognostic variables each model can predict different derived quantities at the interfaces such as stresses and heat fluxes. Future efforts will focus on providing consistent fluxes across the interfaces.

\section{Acknowledgments}

The symbols used for some of the diagrams are courtesy of the Integration and Application Network (ian.umces.edu/symbols),
University of Maryland Center for Environmental Science. Funding is in part from the USGS Carolinas Coastal Change Processes Project. Any use of trade, product, or firm names is for descriptive purposes only and does not imply endorsement by the US Government.

\section{References}

Bender, M.A., Ginis, I., 2000. Real-case simulations of hurricane-ocean interaction using a high-resolution coupled model: effects on hurricane intensity. Monthly Weather Review 128, 917-946.

Bender, M.A., Ginis, I., Tuleya, R., Thomas, B., Marchok, T., 2007. The operational GFDL coupled hurricane-ocean prediction system and a summary of its performance. Monthly Weather Review 135, 3965-3989.

Booij, N., Ris, R.C., Holthuijsen, L.H., 1999. A third-generation wave model for coastal regions. Part I: Model description and validation. Journal of Geophysical Research 104 (C4), 7649-7666.

Chen, S.S., Price, J.F., Zhao, W., Donelan, M.A., Walsh, E.J., 2007. The CBLASTHurricane program and the next-generation fully coupled atmosphere-waveocean models for hurricane research and prediction. Bulletin of the American Meteorological Society 88, 311-317.

Fairall, C.W., Bradley, E.F., Rogers, D.P., Edson, J.B., Young, G.S., 1996. Bulk parameterization of air-sea fluxes for tropical ocean-global atmosphere Coupled-Ocean Atmosphere Response Experiment. Journal of Geophysical Research 101, 3747-3764.

Fan, Y., Ginis, I., Hara, T., 2009a. The effect of wind-wave-current interaction on airsea momentum fluxes and ocean response in tropical cyclones. Journal of Physical Oceanography 39, 1019-1034.

Fan, Y., Ginis, I., Hara, T., Wright, C.W., Walsh, E.J., 2009b. Numerical simulations and observations of surface wave fields under extreme tropical cyclone. Journal of Physical Oceanography 39, 2097-2116.

Ganju, N.K., Schoellhamer, D.H., Jaffe, B.E., 2009. Hindcasting of decadal-timescale estuarine bathymetric change with a tidal-timescale model. Journal of Geophysical Research 114, F04019. doi:10.1029/2008JF001191.

Gemmill, W., Katz, B., Li, X., 2007. Daily Real-Time Global Sea Surface Temperature High Resolution Analysis at NOAA/NCEP. NOAA/NWS/NCEP/MMAB Office Note Number 260, 39 pp.

Haidvogel, D.B., Arango, H.G., Budgell, W.P., Cornuelle, B.D., Curchitser, E., Di Lorenzo, E., Fennel, K., Geyer, W.R., Hermann, A.J., Lanerolle, L., Levin, J., McWilliams, J.C., Miller, A.J., Moore, A.M., Powell, T.M., Shchepetkin, A.F. Sherwood, C.R., Signell, R.P., Warner, J.C., Wilkin, J., 2008. Regional ocean forecasting in terrain-following coordinates: model formulation and skill assessment. Journal of Computational Physics 227, 3595-3624.

Harris, C.K., Sherwood, C.R., Signell, R.P., Bever, A., Warner, J.C., 2008. Sediment dispersal in the northwestern Adriatic Sea. Journal of Geophysical Research, Oceans 113, C11S03. doi:10.1029/2006JC003868.

He, R., Wilkin, J.L., 2006. Tides on the Southeast New England Shelf: a view from a hybrid data assimilative modeling approach. Journal of Geophysical Research 111, C08002. doi:10.1029/2005JC003254.

Holthuijsen, L.H., 2008. Waves in Oceanic and Coastal Waters. Cambridge Press. 387 pp.

Jacob, R., Larson, J., Ong, E., 2005. $M \times N$ Communication and Parallel Interpolation in CCSM Using the Model Coupling Toolkit. Preprint ANL/MCSP1225-0205. Mathematics and Computer Science Division, Argonne National Laboratory, 25 pp.

Jones, P.W., 1998. A Users Guide for SCRIP: A Spherical Coordinate Remapping and Interpolation Package. V 1.4, Los Alamos National Laboratory. http:// climate.lanl.gov/Software/SCRIP/.

Kara, A.B., Metzger, E.J., Bourassa, M.A., 2007. Ocean current and wave effects on wind stress drag coefficient over the global ocean. Geophysical Research Letters 34, L01604. doi:10.1029/2006GL027849.

Loder, J.W., 1980. Topographic rectification of tidal currents on the sides of Georges Bank. Journal of Physical Oceanography 10, 1399-1416.

Loder, J.W., Greenberg, D.A., 1986. Predicted positions of tidal fronts in the Gulf of Maine region. Continental Shelf Research 6, 396-414.

Kirby, J.T., Chen, T-M., 1989. Surface waves on vertically sheared flows: approximate dispersion relations. Journal of Geophysical Research 94, 10131027.

Larson, J., Jacob, R., Ong, E., 2004. The Model Coupling Toolkit: A New Fortran90 Toolkit for Building Multiphysics Parallel Coupled Models. Preprint ANL/MCSP1208-1204. Mathematics and Computer Science Division, Argonne National Laboratory, $25 \mathrm{pp}$

Lesser, G.R., Roelvink, J.A., van Kester, J.A.T.M., Stelling, G.S., 2004. Development and validation of a three-dimensional morphological model. Coastal Engineering 51 (8-9), 883-915.

Mukai, A.Y., Westerink, J.J., Luettich, R.A., 2001. Guidelines for Using the Eastcoast 2001 Database of Tidal Constituents within the Western North Atlantic Ocean, Gulf of Mexico and Caribbean Sea. US Army Corps of Engineers Coastal and Hydraulic Engineering Technical Note (IV-XX). http://cirp.wes.army.mil/cirp/ cetns/wnat/chetn_wnat_101101a-html.htm.

Powell, M.D., Houston, S.H., Amat, L.R., Morisseau-Leroy, N., 1998 (The HRD realtime hurricane wind analysis system). Journal of Wind Engineering and Industrial Aerodynamics 77-78, 53-64 http://www.aoml.noaa.gov/hrd/ Powell/JWEIA2.pdf. 
Shchepetkin, A.F., McWilliams, J.C., 2005. The Regional Ocean Modeling System: a split-explicit, free-surface, topography-following coordinates ocean model. Ocean Modelling 9, 347-404. doi:10.1016/j.ocemod.2004.08.002.

Shchepetkin, A.F., McWilliams, J.C., 2009. Correction and commentary for "Ocean forecasting in terrain-following coordinates: Formulation and skill assessment of the regional ocean modeling system" by Haidvogel et al., J. Comp. Phys. 227, pp. 3595-3624.". Journal of Computational Physics 228, 89859000

Skamarock, W.C., Klemp, J.B., Dudhia, J., Gill, D.O., Barker, D.M., Wang, W., Powers, J.G., 2005. A Description of the Advanced Research WRF Version 2. NCAR Technical Note, NCAR/TN-468+STR.

Taylor, P.K., Yelland, M.J., 2000. The dependence of sea surface roughness on the height and steepness of the waves. Journal of Physical Oceanography 31, 572590.
Warner, J.C., Butman, B., Alexander, P.S., 2008a. Storm-driven sediment transport in Massachusetts Bay. Continental Shelf Research 28, 257-282.

Warner, J.C., Sherwood, C.R., Signell, R.P., Harris, C., Arango, H.G., 2008b. Development of a three-dimensional, regional, coupled wave, current, and sediment-transport model. Computers and Geosciences 34, 1284-1306.

Warner, J.C., Perlin, N., Skyllingstad, E., 2008c. Using the Model Coupling Toolkit to couple earth system models. Environmental Modelling and Software 23, 1240 1249.

Warner, J.C., Geyer, W.R., Arango, H.G., in press. Using a composite grid approach in a complex coastal domain to estimate estuarine residence time. Computers and Geosciences.

Wren, P.A., Leonard, L, 2005. Sediment transport on the mid-continental shelf in Onslow Bay, North Carolina during Hurricane Isabel. Estuarine, Coastal, and Shelf Science 63, 43-56. 